\title{
A Multivariate Model of Biocultural Conservation (6) of Medicinal, Aromatic and Cosmetic (MAC) Plants in Indonesia
}

\author{
L. Jan Slikkerveer
}

\begin{abstract}
One of the major contributions of quantitative ethnobotany as a relatively new approach to the study, analysis and interpretation of ethnobotanical field data has been the provision of valuable information on complicated humanplant relationships, particularly relevant for improved policy planning of plant resource management in the tropics. In addition, quantitative ethnobotany has shown to facilitate the truly comparative study of indigenous knowledge and use of plants by different socio-cultural groups and to provide a reliable basis for the assessment of quantitative impacts of human activities on plants and ecosystems. In the light of the current efforts to build bridges with traditional knowledge, another significant, albeit less studied aspect of the application of a quantitative approach in ethnobotany refers to its increased capacity to strengthen the 'scientific' value of results for the interpretation, understanding and prediction of patterns and processes in human-plant interactions. As in the related 'knowledge-behavior-belief' complex, the latter component still remains problematic for many Western-trained scientists, this paper seeks to further develop a multivariate model of biocultural conservation behavior on the basis of current ongoing research on traditional knowledge and use of MAC pants - jamu - in Sunda, West Java, that could help to bridge the gap. In this model, such 'subjective' individual factors of perceptions, cosmologies and belief systems are statistically transformed into 'objective' system variables for analysis that eventually will enhance the applicability of the outcome variables for improved biocultural conservation projects in the research area, and as such, advance its 'scientific' representation.
\end{abstract}

\section{Introduction}

Following the global concern of the threat of loss of the Earth's biodiversity that has particularly increased since the UN Conference on Environment and Development
(UNCED, Rio de Janeiro 1992), a similar solicitude is now emerging among anthropologists, sociologists and development experts of the approaching loss of closely related forms of cultural diversity in terms of rapidly disappearing local and regional systems of indigenous knowledge and practice of specific groups and communities around the globe. This is giving a major impetus to the documentation and understanding of the newly-developing field of indigenous knowledge systems theory and practice (Slikkerveer 1999a, Warren et al. 1995).

The growing recognition of the close relationship between biodiversity and cultural diversity reflected in indigenous peoples' extensive knowledge concerning the management of animal and plants is also expressed in the Global Biodiversity Strategy (1992) to substantiate the 'inextricable link' between biological and cultural diversity (Posey 1999). This strategy aims at strengthening the sustainable management and conservation of animals, plants as well as humankind's collective knowledge, perceptions and practices encapsulated in the concept of 'biocultural diversity'.

\section{Correspondence}

L.Jan Slikkerveer, Leiden University Branch of the National Herbarium of The Netherlands, Faculty of Sciences, Leiden Ethnosystems and Development Programme (LEAD), Van Steenis Building, Einsteinweg 2, P.O. Box 9514, 2300 RA Leiden, THE NETHERLANDS.

I.j.slikkerveer@umail.leidenuniv.nl

Ethnobotany Research \& Applications 3:127-138 (2005) 
As a result of the recent World Conference on Science, organised by UNESCO and the International Council for Science (ICSU) in 1999 in Budapest, two principal documents - the 'Declaration on Science and the Use of Scientific Knowledge' and the 'Science Agenda Framework for Action' (1999) are not only further underscoring the valuable contribution of:

'...traditional and local knowledge systems as dynamic expressions of perceiving and under standing the world', but also point to the need: ...to preserve, protect, research and promote this cultural heritage and empirical knowledge.' In May 2000, the 'Conference of Parties' (COP) to the Convention on Biological Diversity (CBD) adopted a formal decision at its fifth meeting in Nairobi, Kenya, implementing Article 8(j) that further strengthens the position of the knowledge, innovations and practices of indigenous and local communities as being relevant for the conservation and sustainable use of biological diversity.

Ethnoecology, as a significant discipline encompassing various fields of the study of indigenous people's perceptions and interactions with their environment, has recently developed various theoretical and practical approaches that not only seek to document information on local classifications and taxonomies, but also to contribute to dynamic processes of community development and conservation programs (Martin 1995).

The specific field of ethnobotany as the multidisciplinary study of interactions between people and plants involves contributions from botany, ethnopharmacology and anthropology, as well as from ecology, economics and linguistics. As such, it builds on different methods developed to study and analyze indigenous botanical knowledge and use of plants in a particular culture or community. By consequence, various studies reflect such multidisciplinary orientation in research methodology in ethnobotany. While Given and Harris (1994) developed a practical manual for techniques and methods of ethnobotany and Alexiades (1996) formulated appropriate guidelines for ethnobotanical research, Heinrich (2001) points to the application of a combination of general ethnobotanical and ethnopharmacological methods with specific anthropological and botanical methods. In a previous comparative study on medicinal plants use in Mexico, Heinrich et al. (1998) underscored the importance of a standardised methodology that would allow for intercultural comparison among different groups.

Meanwhile, an increasing number of ethnobotanical studies have been focused on indigenous management systems. These have documented that indigenous methods are often more sustainable than most global, commercially-based practices of resource utilisation. Furthermore that indicate that local knowledge is crucial in the conservation of ecosystems and germplasm of a variety of plants and crops. Some of these studies also highlight the local benefits of ethnobotanical knowledge for the cultural survival of many indigenous peoples (Baines \& Hviding 1992, Brush 1991, Richards 1985, Soleri \& Smith 1994).

Depending on the type of research focus - fundamental or applied - various approaches have further been developed and tested in ethnobotany to document and analyze people's knowledge and practices concerning the use and management of their plant resources. Martin (1995) refers to four major ethnobotanical endeavours:

1. Basic documentation of traditional botanical knowledge;

2. Quantitative evaluation of use and management of botanical resources;

3. Experimental assessment of plant-derived benefits for subsistence and commercial purposes, and

4. Applied projects that seek to maximise the value of ecological knowledge and resources for the local people.

Lewis and Elvin-Lewis (1994) have suggested that the first three approaches would encompass three interrelated phases of future ethnobotanical research: basic, quantitative and experimental ethnobotany. While basic ethnobotany refers to the descriptive compilation and organization of information on indigenous peoples knowledge on useful plants and animals, their local classification systems and their management practices, quantitative ethnobotany goes a step further to develop methods for the quantitative description, evaluation, analysis and comparison of primary data sets (Prance 1991). Experimental ethnobotany involves the use and analysis of biota for the development of medicines and other natural products for industrial and other commercial purposes.

However, given the growing scarcity of ethnobotanical information from intact indigenous peoples on the one hand, and the growing attention for the dynamic processes of acculturation and transculturation among communities which incorporate both localized and global forms of knowledge and practices on the other hand, a more realistic view focuses on the development of a comparative approach of Ethnobotanical Knowledge Systems (EKS). EKs approaches move towards the knowledge and use of plant resources among different cultures and communities. As Alcorn (1994) notes, such resources include ecological principles, plant uses and facts, plant-related technologies, locally adapted crops, agricultural systems, farming values and strategies, and information about local constraints, opportunities and needs. Following a similar comprehensive orientation of the Medicinal, Aromatic and Cosmetic Plants in Indonesia (MACPIN) project in Indonesia, the current research focuses primarily on the comparative study of various ethnobotanical knowledge systems of medicinal, aromatic and cosmetic (MAC) plants (jamu), including both intellectual and material components of the prevailing systems in the research area of West Java. 
Three major, well accepted advantages of quantitative ethnobotany are that it:

1. Provides valuable information on complicated human-plant relationships;

2. Facilitates the truly comparative study of indigenous knowledge and use of plants by different socio-cultural groups; and

3. Provides a reliable basis for the assessment of quantitative impact of human activities on plants and ecosystems, another aspect of quantitative ethnobotany refers to the strengthening of the value of data by applying appropriate methods and techniques of analysis (Höft et al. 1999).

Additionally, Philips and Gentry (1993a,b) suggest that refined quantitative data collection and analysis improves ethnobotany as a discipline and also enhances its image among other scientists. This serves to strengthen the indicative and predictive value of research data. Such links were demonstrated through the various contributions to the conference on 'Building Bridges with Traditional Knowledge - International Summit Meeting on Issues Involving Indigenous Peoples, Conservation, Sustainable Development and Ethnoscience' that was held in Honolulu, Hawai'i in June 2001. An example of the contributions in the summit meeting is the work of Stanford and Eglee Zent. In their comprehensive treatise on the appropriateness, adequacy and determinacy of methods that seek to understand the dynamic aspects of indigenous knowledge, they (Zent \& Zent 2001) presented a well-documented assessment of qualitative and quantitative approaches that include both advanced methods and techniques for collecting data and their analysis. This paper seeks to further elaborate on the use and application of multivariate analysis techniques, particularly the non-linear canonical correlation analysis of factors and the associated multivariate model that is currently being developed to contribute to indigenous biocultural conservation policies of MAC plants in Indonesia.

Previously (Slikkerveer 2001) a similar quantitative orientation was presented towards the understanding and prediction of the Evidence-Based Conservation (EBC) behavior of the indigenous people on the basis of joint ongoing medical ethnobotanical research on the knowledge and use of medicinal, aromatic and cosmetic (MAC) plants in Mount Halimun area of West Java, Indonesia. This paper seeks to focus on the issue of increasing the indicative and predictive value of factors involved in local people's decision-making environment on the basis of the application of a corresponding multivariate analysis.

\section{The 'Knowledge-Practice- Belief' Complex}

The valuable knowledge of indigenous and local peoples about the use and maintenance of their resources and the environment has accumulated over many generations, and often includes local practices for biodiversity conservation. Such practices are generally rooted in a combination of local ecological knowledge and belief systems that has developed over a lengthy period of time.

Indigenous knowledge about biodiversity management and conservation is still difficult for many researchers to understand. It is, as Wells (1995) notes: 'vital, however, that the value of the 'knowledge-practice-belief' complex of indigenous peoples as it relates to biodiversity management is fully recognized.' Although in this complex of local biodiversity conservation a full comprehension of the underlying belief systems, cosmologies and indigenous perceptions of nature and culture is still missing in the absence of adequate 'scientific' parameters, the 'outcome' of these for some 'invisible' factors in terms of ecologically sustainable use of resources has shown undeniable empirical value.

The conservation of indigenous knowledge has successfully been achieved by the promotion of community-based resource management systems among a number of indigenous peoples and communities, such as the Kayapo Indians in Brazil (Posey 1984) and the Runa Indians in the Ecuador (Irvine 1989). Although indigenous peoples have recently been referred to as potential resource managers of tropical forest ecosystems, their relationship with conservationists remain controversial. For instance, Aumeeruddy (1994) analyzed the situation of agroforestry in relation to the Kirinci National Park under pressure in Sumatra, Indonesia and noticed that the recognition of the knowledge and practices of local farmers by the park's conservationist reduced the tensions between the two opposing parties substantially, creating new opportunities for collaborative development. This links up well with the widely accepted recognition of local participation in rural development and participatory approaches to biodiversity management (Wells \& Brandon 1993, West \& Brechin 1991).

There is continued reluctance of some mainstream scientists to recognise and respect indigenous knowledge systems in a variety of contexts. This is largely based on such stereotyped dichotomies as 'subjective' versus 'objective' orientations, 'qualitative' versus 'quantitative' techniques, 'practical' versus 'theoretical' approaches, and 'oral' versus 'written' sources. These have contributed to the ethnocentric views from 'science' towards other knowledge systems. The three related elements of the above mentioned complex therefore merit some further attention.

The tools to assess and measure the concept of 'knowledge' in any society have been sufficiently developed along linguistic, philosophical and socio-cultural lines to allow for valid comparison. By consequence, several studies have sought to identify the similarities and differences between 'scientific' and indigenous knowledge. Although most of these studies tend to draw the attention to 
the differences between these knowledge systems, they substantiate the convenient use of knowledge assessment as a generally applicable parameter (McNeely 1994, Scoones \& Thompson 1994).

At the local level, other approaches have led to processual studies that seek to understand the creation, transformation, and communication of knowledge at the local level (Martin 1995, Zent \& Zent 2001). In ethnobotanical methodology, plant knowledge is mainly recorded along local classification and taxonomy systems, and separated from applied knowledge of use of plant parts and specific diseases. Further demarcation encompasses commonly shared knowledge of members of a community that is of ten encoded in formal vocabularies, with specific knowledge tending to reflect personal experience and wisdom (Ellen 1994). In the differentiation of tacit and explicit indigenous knowledge, the first refers to knowledge embedded in taboos and local institutions, while the latter rests with local experts such as healers. Cox (2001) showed that it is particular tacit knowledge that is important for the conservation of biodiversity.

In recent years, some studies have focused on indigenous experimentation and innovation in relation to the development of ethnobotanical knowledge systems, showing their dynamic and adaptive aspects (Soleri \& Cleveland 1993). Current issues related to the generation, exchange and utilisation of knowledge at global levels have been well analyzed within the context of development cooperation (Beal et al. 1986). Beal et al. (1986) rightly regard 'knowledge' as the primary cognitive part of any given culture. They render indigenous knowledge as basically referring to a system of local perceptions, practices, technologies and skills that have developed over generations and as such are unique to a specific culture or region. The overriding conclusion of all these studies is that indigenous knowledge has provided and still has great potential to contribute to the development of various aspects of global knowledge and technology.

Similarly, the concept of 'behavior' has received much attention from among different disciplines, resulting in elaborate methods and techniques for the observation, study and analysis of patterns of human behavior within various domains of life. Most methods to compile empirical information of patterns of behavior are centred around participant observation, monitoring techniques, life histories and case studies.

Within the context of ethnobotany, such behavior is generally assessed in relation to the use, management and conservation of plant resources by indigenous and local peoples. It is often recorded and quantified as 'use reports', either by participant observation or in a retrospective way. An illustrative example of ethnobotanists involved in the study of local people's conservation behavior is provided by the People and Plants Initiative that was established in 1992 by WWF, UNESCO, and Royal Botanic Garden at Kew as global programme to promote the sustainable and equitable use of plant resources. Projects include i.a. the 'Beni Biosphere Reserve' in Bolivia, 'Projeto Nordeste: Local Plants for Local People' in Brazil, 'Harvesting of Prunus africana' in Cameroon, and Kinabalu Ethnobotany Project in Sabah, Malaysia (People and Plants Initiative1993).

Among the programme's activities such as the training of local people and the support for community development, a network of data bases on local plant use and conservation is providing valuable information on local practices and methods. As such, the programme has also contributed to the further development of participatory ethnobotanical research where Western and local researchers work together for economic development and conservation of resources.

As regards the third concept of 'belief', a few studies have shown that such complex patterns of indigenous use, management and conservation of plants essentially are based on the interaction between bio-physical and sociocultural factors that determine what Cotton (1998) refers to as the 'individual's decision-making environment' (Ellen 1994, Karim 1981, Richards 1994). Since this, in turn, is based on the indigenous perceptions of the natural world including local beliefs and cosmologies which often have a strong influence on the utilisation behavior of resources, it is important that these are well understood. The different factors that seem to influence local environmental perceptions - and as such people's behavior - include not only such bio-physical and sociological, but also spiritual and personal factors.

As Cotton (1998:245) rightly notes, this phenomenon has, however, received relatively little attention: 'Unfortunately, this aspect of ethnobotanical study is one which has often been overlooked in utilitarian surveys, yet which is of singular importance, in particularly where traditional knowledge is to be applied cross-culturally..'

Despite the fact that the in-depth study of such local perceptions of the natural world has recently extended to include both the etic approaches towards the objective 'outsiders' assessment of the environment, as well as the emic approaches towards the subjective 'insiders' perception, the understanding of the socio-cultural and spiritual aspects of biodiversity management and conservation remains problematic.

From an anthropological point of view, the interrelationships between cultural and spiritual values of plants and other resources that are part of local people's cosmology have only recently been studied in conjunction with their practices, supporting that indigenous beliefs have a significant influence on people's local use and management behavior (Elisabetsky \& Posey 1994). As Posey (1999) 
notes, anthropologists have now a major task to further document and study the local context of these cultural and spiritual values and beliefs underlying indigenous knowledge and practice that - as a result of lack of understanding - so far have largely contributed to the artificial gap between 'scientific' and indigenous knowledge systems.

In their contribution to such task, ethnobotanists involved in the sustainable use and conservation of plant resources are refining their research methodology, in which quantitative ethnobotany can further strengthen the scientific base for future policy planning and implementation.

\section{The Advance of Quantitative Ethnobotany}

In the current efforts to increase the mutual understanding between global and local knowledge, a number of ethnobotanists - in collaboration with local peoples and extension agents - focus to achieve further integration and synergy among these systems in a variety of ways. In addition to the conventional descriptive methods to record local classifications and uses of plant species, recent developments in data collection and analysis have taken ethnobotanical research methodology into advanced qualitative and quantitative approaches.

As mentioned before, Lewis and Elvin-Lewis (1994) have suggested that these approaches refer to three interrelated phases of future ethnobotanical research: basic, quantitative and experimental ethnobotany. Particularly, recent advances in quantitative ethnobotany attempt to improve the field of study by introducing and extending quantitative methods in both data collection and interpretation of results.

Prance (1991) introduced this new approach in 1987, and it is defined by Philips and Gentry $(1993 a, b)$ as: 'the application of quantitative techniques to the direct analysis of contemporary plant use data'. While in general, quantitative methods and techniques strengthen the indicative and predictive value of factors or variables in ethnobotanical research, they also allow for cross-cultural comparison of data between and among different ethno-linguistic groups and communities. In this way, increased understanding of phenomena and processes will contribute to improved resource conservation and sustainable community development.

Since quantitative analysis depends to a large degree on the availability and reliability of quantitative field data, refinement and extension of data collection methods and techniques have similarly attracted the attention of ethnobotanist. This has resulted in the development of a variety of methods, ranging from structured and semi-structured interviews, participant observation, household surveys, various forms of comparative methods, structured interac- tions and analytical tools. It includes specific data collecting methods to compile an ethnobotanical data set of the research area such as plant collections, local classification systems, socio-demographic information, indigenous botanical knowledge and use and management behavior of participants.

The use of analytical tools has increased the compilation of detailed quantitative data on specific subjects, and involve the use of preference ranking, matrix ranking, paired comparisons and triad comparisons (Martin 1995).

With regard to the processing and analyzing techniques of data, the recent advance of statistical methods and computerised data theory have enabled ethnobotanists considerably to proceed from simple enumerations to complex multivariate analysis that help to understand complex relations and interactions among different factors involved in the knowledge, use and conservation of plant resources.

Höft et al. (1999) list a number of types of ethnobotanical data where the application of multivariate analysis is indicated. It includes i.a. the interpretation of knowledge and use of pants by different ethnic, social or gender groups, and the assessment of the quantitative impact of human uses on growth and regeneration patterns, of environmental factors on plants, and of agricultural techniques on plants. In their review, statistical applications may in general be classified into two broad categories: 1) sets of data where the measurements are taken only to one attribute or response variable allowing for univariate analysis techniques; and 2) sets of data where the measurements are taken simultaneously on more than one variable allowing for multivariate analysis techniques.

As the multivariate analysis technique is generally used to make large data sets accessible, recognise structures, and explain and predict patterns among variables, Johnson and Wichern (1988) identify five basic applications: 1) data reduction or structural simplification; 2) sorting and grouping; 3) explaining relationships among variables; 4) prediction, and 5) testing of hypotheses While the multivariate analysis techniques for these applications are derived from a rather simple linear mathematical model, the Multivariate General Linear Hypothesis (MGLH), used for linear models for classification and clustering, ordination, variance, regression, correlation and log-linear modelling (Höft et al. 1999). The selection of the most appropriate methodology to achieve maximum results depends on both the objectives of the research and the type of ethnobotanical study.

As a result of increasing complexity of quantitative ethnobotanical studies in which the relationships among several variables or groups of variables have to be assessed and interpreted, the use of the computer is imminent. Various useful computer packages have been devel- 
oped, including SPSS (1998), TWINSPAN (Hill 1979) and CANALS (Van der Burg 1983).

As we will see in the next paragraph, the selection of the model appropriate for the explanation and prediction of biocultural conservation behavior in the study area of West Java is based on the research interest into the quantitative relationships among various groups of independent background and intervening variables vis-a-vis the dependent behavior variables. It draws on lessons learned from previous similar research pertaining to the quantitative analysis of patterns of utilisation behavior of the pluralistic medical traditions in the Horn of Africa by different ethnic groups, and the quantitative analysis of patterns of local agricultural conservation behavior of the kasepuhan people in Mount Halimun area of West Java (Slikkerveer 1991, 1996, 1997, 1999a,b).

In this model, such 'subjective' individual factors of perceptions, cosmologies and belief systems are statistically transformed into 'objective' system variables for analysis and comparison that eventually will enhance the applicability of the outcome variables for improved biocultural conservation projects in the research area, and as such, advance its 'scientific' representation.

\section{The Model: From Bivariate to Multivariate Analysis}

After the identification, collection and organization of the different qualitative and quantitative data, the type of application of multivariate and statistical analysis is influenced by the research interest of the study. A simple statistical analysis, in which a data matrix is constructed with objects as rows and variables as columns, the basic linear technique to relate the first and the second data set is called a 'bivariate canonical correlation analysis'. This technique reveals possible interaction between one independent variable - for instance perceived disease - with one dependent variable for instance use of a plant species.

Among the most common multivariate analysis techniques are the basic correlation analysis to measure the general relationships among variables, cluster analysis to assess similarities or dissimilarities among variables, principal component analysis to determine variance among variables, and regression analysis to establish quantitative relationships among variables and prediction. The latter regression analysis allows for predicting values of response, dependent variables from a group of explanatory, independent variables, and is as such appropriate for the explanation and prediction of behavior as a dependent variable from a group of independent background (i.e. predictor variables). In addition, multiple regression models also encompasses interaction terms between and among variables.

For the measurement of the predicting value of different sets (or 'blocks') of background variables in interaction with each other and with a set (or 'block') of intervening variables, the choice of a non-linear correlation analysis has the advantage that it is a technique which may lead to different solutions from different starting points (Van der Burg 1983).

In this application, the selected multivariate analysis is able to cover all the variables in the survey without discriminating between variables or 'blocks' of variables, and allows for drawing conclusions on correlation, interaction and predictability using the canonical correlation analysis of the total number of variables. However, if we want to develop an explanatory model of conservation behavior of medicinal plants, multivariate analysis should be used to examine the correlation among 'blocks' of independent background variables with the 'blocks' of dependent conservation behavior variables of medicinal plants in the model.

Although such model could also be developed as a pathway model using a linear partial canonical correlation analysis, a non-linear correlation analysis (CANALS) is preferred as it increases the predicting value on plant use and conservation behavior by respondents in the survey from an increasing number of background and intervening variables.

The model of biocultural conservation behavior, in which the calculated correlation coefficients can be indicated separately could be constructed on the basis of the position and interaction among 'blocks' of various groupings of independent, intervening and dependent variables, as shown in Figure 1.

A further understanding of the complex coherence between variables and their accompanying observations or categories can be achieved by projecting the correlations as points onto the space of the canonical variates known as the canonical space. If the variable points are geographically connected with zero, a vector diagram is created that shows the links between the variables and the canonical variates. The length of the vectors indicate the relative importance of the variables.

As an example, Figure 2 illustrates the application of such projection in the plot of 19 optimally scaled variables in the canonical space of the second solution from the survey data of the preceding RUL/22 Project in Ethiopia. It shows not only that the variables ethnic affiliation ETHN) and religion (RELIG) express the strongest coherence with the use of traditional medicine, but also that the traditional disease classification distinctly points to the use of traditional medicine (Slikkerveer 1991).

Although most multivariate models tend to focus on linear relationships between variables, the non-linear analysis increases the value of the relevant variables, relevant in the discussion of increasing the value of biocultural conservation factors including the 'knowledge-practice-belief' complex. In fact, the non-linear multivariate techniques can be regarded as two-step techniques: non-linear transformation 


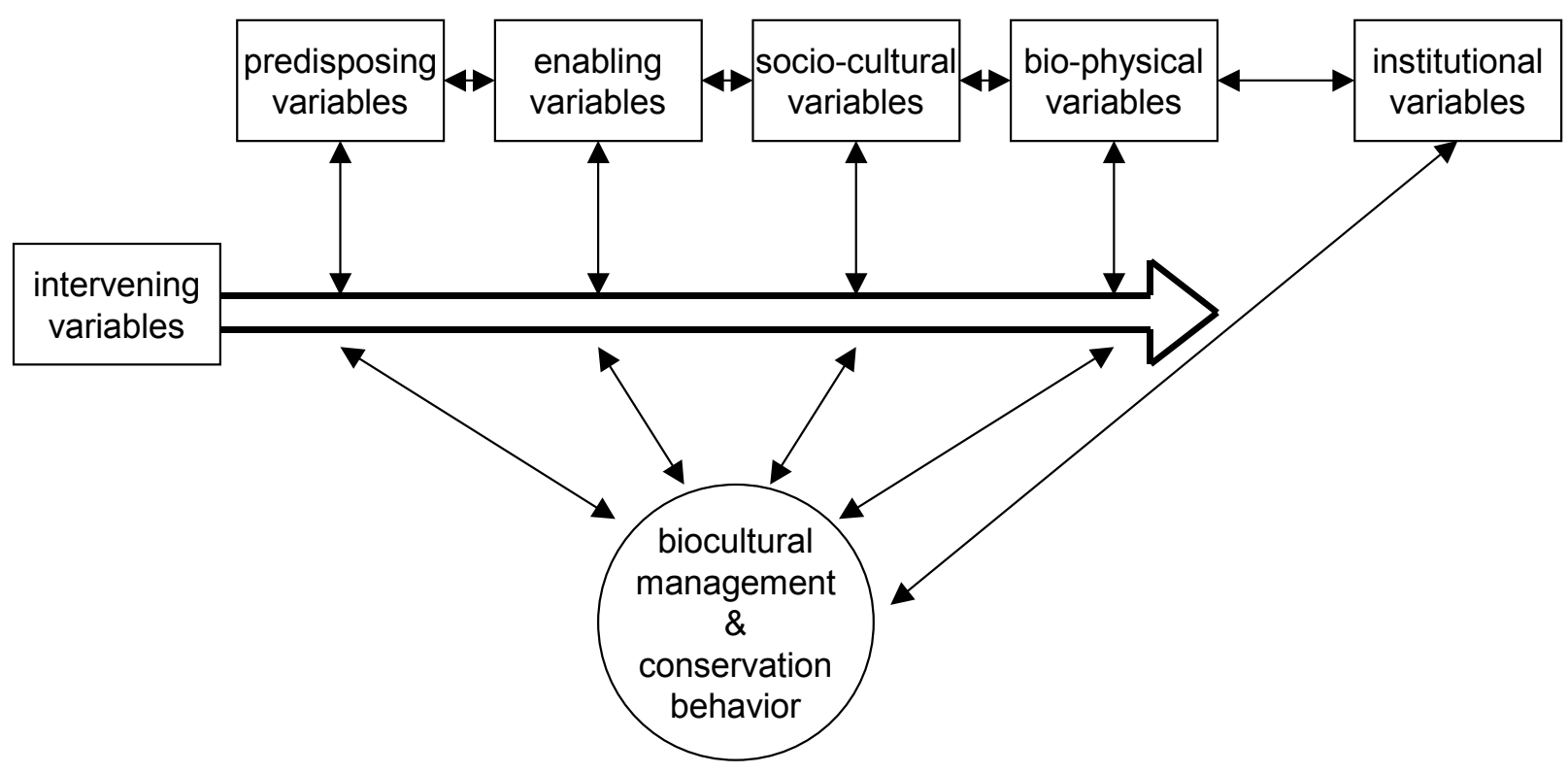

Figure 1. Multivariate model of biocultural conservation behaviour in developing countries

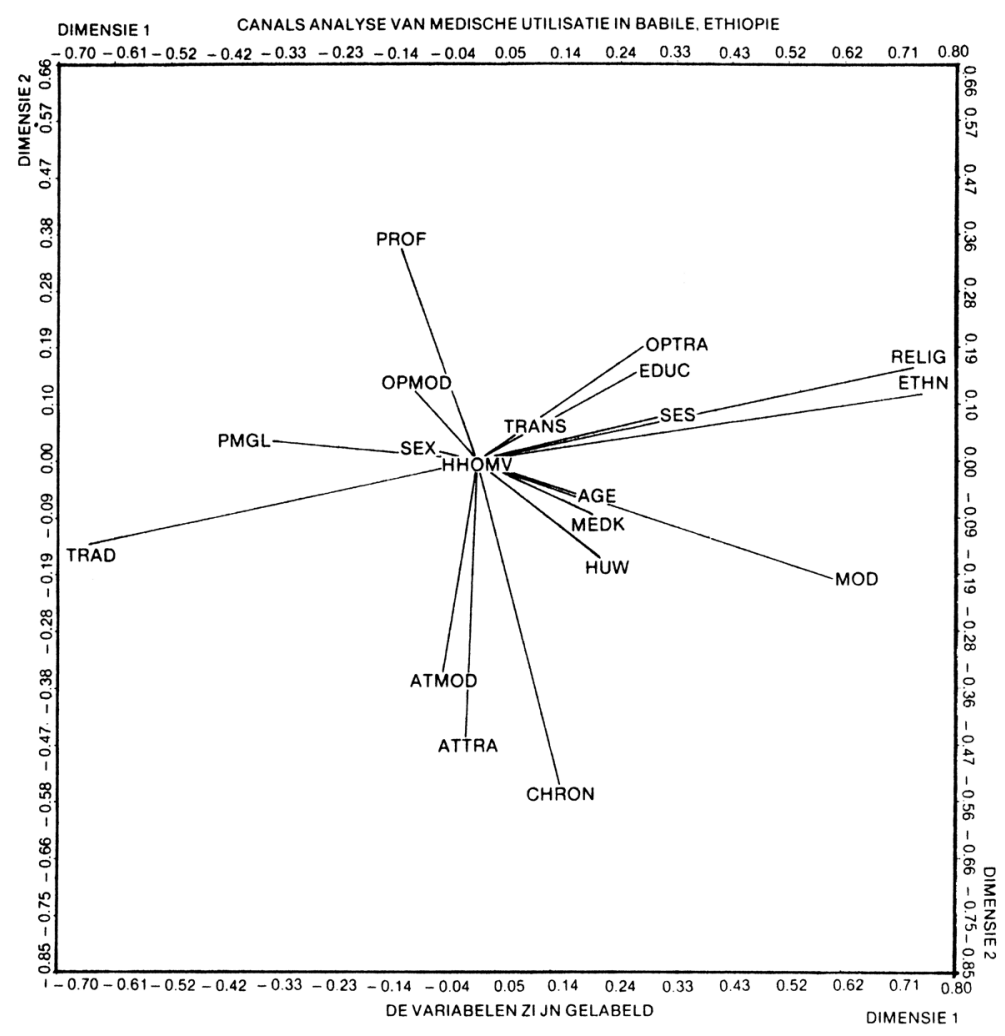

Figure 2. CANALS analysis of health care utilisation in Ethiopia: Projection of the optimally scaled variables onto the canonical space of the second solution. Variables need to be defined here since only $\mathbf{2}$ are defined in the text. Perhaps these can be referenced with abbreviations in table 1? 


\begin{tabular}{|c|c|c|c|}
\hline \multirow{26}{*}{$\begin{array}{l}\text { Independent variables } \\
\text { at the individual level }\end{array}$} & \multirow{12}{*}{$\begin{array}{l}\text { predisposing } \\
\text { factors }\end{array}$} & \multirow[t]{5}{*}{ psycho-social factors } & knowledge \\
\hline & & & ideas \\
\hline & & & beliefs \\
\hline & & & attitudes \\
\hline & & & opinions \\
\hline & & \multirow[t]{7}{*}{ socio-demographic factors } & $\operatorname{sex}$ \\
\hline & & & age \\
\hline & & & education \\
\hline & & & ethnicity \\
\hline & & & religion \\
\hline & & & profession \\
\hline & & & marital status \\
\hline & \multirow{7}{*}{\multicolumn{2}{|c|}{ enabling factors }} & SES \\
\hline & & & family income \\
\hline & & & type of house \\
\hline & & & value of tools \\
\hline & & & area of land \\
\hline & & & livestock \\
\hline & & & household budget \\
\hline & \multirow{7}{*}{\multicolumn{2}{|c|}{ socio-cultural factors }} & use-values \\
\hline & & & norms \\
\hline & & & myths \\
\hline & & & taboos \\
\hline & & & cosmovisions \\
\hline & & & classifications \\
\hline & & & taxonomies \\
\hline \multirow{11}{*}{$\begin{array}{l}\text { independent variables } \\
\text { at the system level }\end{array}$} & \multirow{7}{*}{\multicolumn{2}{|c|}{ bio-physical factors }} & plant and animal \\
\hline & & & species/resources \\
\hline & & & vegetation types \\
\hline & & & eco-zones \\
\hline & & & rainfall \\
\hline & & & altitude \\
\hline & & & soil types \\
\hline & \multirow{4}{*}{\multicolumn{2}{|c|}{ institutional factors }} & local \& national \\
\hline & & & administrative structures \\
\hline & & & local institutions \\
\hline & & & representations \\
\hline \multirow[t]{4}{*}{ intervening variables } & \multirow{4}{*}{\multicolumn{2}{|c|}{ policy \& planning factors }} & government \\
\hline & & & policy planning \& implementation laws \\
\hline & & & regulations \\
\hline & & & controls \\
\hline \multirow[t]{3}{*}{ dependent variables } & \multirow{3}{*}{\multicolumn{2}{|c|}{ conservation behaviour factors }} & biocultural \\
\hline & & & conservation \\
\hline & & & behaviour pattern \\
\hline
\end{tabular}


of variables into optimally scaled variables, followed by application of the multivariate analysis to the optimally scaled variables. In accordance with the model, relevant factors have been grouped and divided into blocks of variables in Table 1.

\section{Indonesia and the RUL/22 and INDAKS Projects}

Natural resource management at community level that recently has received increased international attention from ethnobotanist and anthropologists, (CBNRM) is yet to be developed in Indonesia, where the use, exploitation and management of resources has largely remained under the control of the central government, often granting commercial enterprises concessions for large-scale use. Despite this situation, indigenous peoples of Indonesia possess and practice a wealth of traditional environmental knowledge including the management and conservation of biodiversity that is most valuable for future sustainable development. As elsewhere around the globe, this knowledge has recently come under threat of extinction, partly as it is not yet completely identified, reordered and analyzed, and partly because of the ongoing process of globalization.

Based on a recent assessment by Aliadi (2001) of 159 papers from the 1992 and 1995 National Ethnobotany Workshop and Seminar Proceedings to determine the nature of the ethnobotany research being done in Indonesia, and the techniques that are being employed to document knowledge from local people, he notes : 'Ethnobotany provides the tools for the documentation of village people's knowledge, especially related to plant utilisation'.

In this context, he continues to point out, that: '..ethnobotany research in Indonesia has been mostly explorative, and primarily what is being sought is information needed by the researchers', raising the issue of a lack of participatory research and the related questions of ethics, intellectual property rights and equal benefit sharing. As Aliadi (2001) is making a strong plea for the development of a methodological approach that is more participatory, in which researchers will act more as facilitators, it is clear that such endeavour should go beyond the qualitative methods of data analysis which have been largely used so far in ethnobotany studies.

Among the first applications of quantitative methods for the multivariate analysis of local health utilisation patterns was the 'Rural Health in Ethiopia Project' (RUL/22), in which not only the influence of various groups of background characteristics on local people's utilisation behavior was analyzed, but also a method was developed to measure the mutual interaction processes among various groups of factors vis-a-vis the resulting utilisation factors. Remarkably, the analytic multivariate model of transcultural health care utilisation substantiated the significant role and strength of socio-cultural determinants - ethnicity and religion - that eventually constitute the 'illness management group' at the community level (Slikkerveer 1991).

In this applied-oriented research project, the results were eventually integrated into a regional programme of comprehensive health care policy planning, putting an emphasis on health education, PHC training and collaboration with traditional healers in the research area of Hararghe, East Ethiopia.

Later on, two ethnobotany studies were carried out in the Archipelago, including research on traditional knowledge and use of jamu as indigenous medicine for self-reliance in Sunda, West Java (1991-1993), followed by the joint Indonesian-Netherlands research programme on 'Indigenous Agricultural Knowledge Systems for Sustainable Development' (INDAKS) (1993-1997) in the Mount Halimun Natural Preserve Region of West Java.

Currently, a pilot project is underway in West Java within the context of the 'Medicinal, Aromatic and Cosmetic Plants in Indonesia' Programme (MACPIN) in which one of the objectives is to strengthen the ethnobotanical research by introducing a quantitative methodology (Adimihardja \& Clemens 1999, Slikkerveer \& Slikkerveer 1994, Slikkerveer 1999a).

Recent ethnobotanical research among the traditional Sundanese people called kasepuhan in the Mount Halimun area, West Java has indicated that the traditional healers (dukun) and traditional midwives (bidan) as primary guardians of local medicinal plant knowledge and practice tend to include in their use of plant resources specific traditional taboos, rituals and restrictions as regards the careful management, collection and harvesting of certain MAC plant species.

As in other parts of Indonesia, there still exists among the members of the traditional communities in the area strong tradition of agricultural, environmental and botanical knowledge, beliefs and practices evolved from a generations-long life-style which has remained close to nature. Their experience is embedded in the local cosmology that as a specific indigenous philosophy of nature and the environment continues to influence their traditional way of using and managing their natural resources in a non-exploitative, sustainable way (Adimihardja \& Clemens 1999, Slikkerveer 1999a).

Joint research over the past few years has not only assessed, documented and analyzed these strong belief systems of the kasepuhan peoples' cosmology on their natural resources management methods, but also revealed the forceful position of the principles and practices of maintaining and protecting the diversity of both wild and non-wild food, medicinal and aromatic plants in the region (Slikkerveer 1997). Interestingly, these local principles 
have been able to help to maintain the resources as traditional healers have practised a method of 'conservationthrough-use' where particular attention is paid to a kind of 'recompensation' to nature in terms of the replanting or domestication of certain wild medicinal plants in specifically designated forest areas. Iskandar and Ellen (1999) document the significant role that cultural practices play in the maintenance of biodiversity in traditional rice landraces among the Baduy people living in West Java.

\section{Conclusion}

In addition to the so far recognized advantages of quantitative ethnobotany for the study, analysis and interpretation of ethnobotanical field data - improved information, extended comparison and enhanced impact assessment in the field of complicated human-plant relationships -the use of advanced multivariate analysis techniques (MAT) has a role to play in further strengthening quantitative ethnobotany, as it contributes:

- to understand, explain an predict patterns of Evidence-based Biocultural Conservation (EBC);

- $\quad$ to strengthen the role and position of related factors in the 'Knowledge-Practice-Belief' complex, especially the socio-cultural variables (myth, taboos, spirits, etc.).

In this way, the quantitative approach of multivariate analysis techniques strengthens the field of ethnobotanical knowledge systems (EKS), and as such provides a contribution to the central issue of 'Building Bridges with Traditional Knowledge'.

\section{Acknowledgements}

The author wishes to acknowledge the contributions from Dr. W.H.J.C. Dechering and Drs. A de Groot at Leiden University, and express his gratitude for the kind support of the Martha Tilaar Foundation in The Netherlands. The INDAKS research team is grateful for the kind contribution of the people of the kasepuhan community in Mount Halimun area to the project.

\section{Literature Cited}

Adimihardja, K. \& M. Clemens. 1999. Editors of Indigenous Knowledge Systems Research \& Development Studies, No. 3, UPT.INRIK, Bandung.

Alcorn, J.B. 1994. Ethnobotanical Knowledge Systems A Resource for Meeting Rural Development Goals. Pp. 1-13 in The Cultural Dimension of Development: Indigenous Knowledge Systems. Edited by D.M. Warren, L.J. Slikkerveer \& D.W. Brokensha. IT Studies in Indigenous Knowledge and Development, Intermediate Technology Publications, London.
Alexiades, M. 1996. Selected Guidelines for Ethnobotanical Research: A Field Manual. Advances in Economic Botany 10. New York Botanic Garden, Bronx, New York.

Aliadi, A. 2001. The Role of Ethnobotany in the Documentation of the Diversity of Villager's Knowledge about Natural Resources. Paper presented to the INRIK Workshop, Bandung, Indonesia.

Aumeeruddy, Y. 1994. Local Representations and Management of Agroforests on the Periphery of Kirinci Seblat National Park. People and Plants Working Paper 3, WWF/ UNESCO/Kew, Paris.

Baines, G. \& E. Hviding. 1992. Traditional Environmental Knowledge from the Marovo Area of the Solomon Islands. Pp. 91-110 in Lore: Capturing Traditional Environmental Knowledge. Edited by M. Johnson. Dene Cultural Institute, Fort Hay, Canada.

Beal, G., W. Dissanayaka \& S. Konoshima. 1986. Editors of Knowledge Generation, Exchange, and Utilisation. Westview Press, London.

Brush, S.B. 1991. A Farmer-based Approach to Conserving Crop Germplasm. Economic Botany 45:153-165.

COP. 2000. Conference of Parties' to the Convention on Biological Diversity. United Nations Working Group. Nairobi, Kenya.

Cotton, C.M. 1998. Ethnobotany: Principles and Applications. John Wiley and Sons, Chichester.

Cox, P.A. 2001. Will Tribal Knowledge Survive the Millenium? Science 287:44-45.

Declaration on Science and the Use of Scientific Knowledge. 1999. World Conference on Science, UNESCO and ICSU, Budapest.

Elisabetsky, E. \& D.A. Posey. 1994. Ethnopharmacological Search for Antiviral Compounds: Treatment of Gastrointestinal Disorders by Kayapo Medical Specialists. Pp 77-90 in Ethnobotany and the Search for New Drugs. Edited by D.J. Chadwick \& J. Marsh. Ciba Foundation Symposium 185. Wiley, Chichester.

Ellen, R.F. 1994. Putting Plants in their Place: Anthropological Approaches to Understanding the Ethnobotanical Knowledge of Rainforest Populations. Unpublished paper presented at the UBD-RGS Conference.

Given, D.R. \& W. Harris. 1994. Techniques and Methods of Ethnobotany. Commonwealth Secretariat, London, UK.

Global Biodiversity Strategy. 1992. WRI/IUCN/UNEP. 
Heinrich, M. 2001. Ethnopharmazie und Ethnobotanik: Eine Einfuhrung, Wissenschaftliche Verlagsgesellschaft $\mathrm{MBH}$ Stuttgart.

Heinrich, M., A. Ankli, B. Frei, C. Weimann \& O. Sticher. 1998. Medicinal Plants in Mexico: Healers' Consensus and Cultural Importance. Social Science and Medicine 47:1859-1889.

Hill, M.O. 1979. TWINSPAN, A FORTRAN Program for Arranging Multivariate Data in an Ordered Two-way Table by Classification of the Individuals and Attributes. Section Ecology and Systematics, Cornell University, Ithaca.

Höft, M., S.K. Barik \& A.M. Lykke. 1999. Quantitative Ethnobotany: Applications of Multivariate and Statistical analyses in Ethnobotany. People and Plants Working Paper 6, WWF/UNESCO/Kew, Paris.

Irvine, D. 1989. Succession Management and Resource Distribution in an Amazonian Rainforest. Pp. 223-237 in Resource Management in Amazonia: Indigenous and Folk Strategies. Edited by D.A. Posey \& W. Balée. Advances in Economic Botany 7. New York Botanic Garden, New York.

Iskandar, J. \& R. Ellen. 1999. In Situ Conservation of Rice Landraces among the Baduy of West Java. Journal of Ethnobiology 19:97-125.

Johnson, R.A. \& D.W. Wichern. 1988. Applied Multivariate Statistical Analysis. Prentice Hall, Englewood Cliffs, New Jersey.

Karim, W.J.B. 1981. Ma'Betisék Concepts of Living Things. The Athlone Press, Humanities Press, New Jersey.

Lewis, W.H. \& M.P. Elvin-Lewis. 1994. Basic, Quantitative and Experimental Research Phases of future Ethnobotany with reference to the Medicinal Plants of South America. Pp. 60-78 in Ethnobotany and the Search for New Drugs. D.J. Chadwick \& J. Marsh. Ciba Foundation Symposium 185. Wiley, Chichester.

Martin, G.J. 1995. Ethnobotany: A Peoples and Plants Conservation Manual. Chapman and Hall, London, UK.

McNeely, J.A. 1994. Lessons from the Past: Forests and Biodiversity. Biodiversity and Conservation 3:3-20.

People and Plants Initiative. 1993. People and Plants Inititive of the World Wildlife Fund, UNESCO and Royal Botanic Gardens, Kew, Paris.

Philips, O.L.B. \& A.H. Gentry. 1993a. The Useful Plants of Tambopata, Peru. I: Statistical Hypothesis Tests with a New Quantitative Technique. Economic Botany 47:15-32.
Philips, O.L.B. \& A.H. Gentry. 1993b. The Useful Plants of Tambopata, Peru. II: Additional Hypothesis Testing in Quantitative Ethnobotany. Economic Botany 47: 5-32.

Posey, D.A. 1984. A Preliminary Report on Diversified Management of Tropical Forest by the Kayapo Indians of the Brazilian Amazon. Pp. 112-126 in Ethnobotany in the Neotropics. Edited by G.T. Prance \& J.A. Kallunki. Advances in Economic Botany 1. New York Botanic Garden Press, New York.

Posey, D.A. 1999. Editor of Cultural and Spiritual Values of Biodiversity: A Complementary Contribution to the Global Biodiversity Assessment. UNEP/Intermediate Technology Publications, Nairobi.

Prance, G.T. 1991. What is Ethnobotany Today? Journal of Ethnopharmacology 32:209-216.

Richards, P. 1985. Indigenous Agricultural Revolution. Unwim Hyman, London.

Richards, P. 1994 Local Knowledge Formation and Validation: The Case of Rice Production in Sierra Leone. Pp. 39-51 in Beyond Farmer First: Rural People's Knowledge, Agricultural Research and Extension Practice. Edited by I. Scoones \& J. Thompson. ITP, London.

Science Agenda Framework for Action. 1999. World Conference on Science, UNESCO and ICSU, Budapest.

Scoones, I. \& J. Thompson. 1994. Knowledge, Power and Agriculture - Towards a Theoretical Understanding. Pp. 16-32 in Beyond Farmer First: Rural People's Knowledge, Agricultural Research and Extension Practice. Edited by I. Scoones \& J. Thompson. ITP, London.

Slikkerveer, L.J. 1991. Plural Medical Systems in The Horn of Africa: The Legacy of 'Sheikh' Hippocrates. Kegan Paul International, London.

Slikkerveer, L.J. 1996. INDAKS Project, Progress Report No. 5 (1/1/96 - 30/6/1996), LEAD, Leiden University.

Slikkerveer, L.J. 1997. The Use of Multivariate Analysis for the Design of Comparative Models for Indigenous Agricultural Knowledge and Practice in Indonesia. Paper presented at the INDAKS Workshop on 'Indigenous Agricultural Knowledge Systems', LEAD, Leiden University, 1927 June 1997.

Slikkerveer, L.J. 1999a. Growing Recognition of Indigenous Knowledge Systems in the Context of Development: A New Challenge for Indonesia. Pp. 15-23 in Indigenous Knowledge Systems Research \& Development Studies, No. 3, Edited by K. Adimihardja \& M. Clemens. UPT.INRIK, Bandung. 
Slikkerveer, L.J. 1999b. Ethnoscience: 'TEK' and its Application to Conservation. Pp. 167-260 in Cultural and Spiritual Values of Biodiversity: A Complementary to the Global Biodiversity Assessment. Edited by D.A. Posey. UNEP/ ITP, London.

Slikkerveer, L.J. 2001. The Rise of Jamu: in Indonesia: A Contribution of Medical Ethnobotanical Knowledge Systems to a Model of Evidence-based Biocultural Conservation. Paper presented at the Seminar on 'Innovative Wisdom: The impact of Traditional Knowledge on Science, Conservation and Development', GBD/ICE/UNESCO/IPGRI, White Oak Plantation, Yulee, Florida.

Slikkerveer, L.J. \& M.K.L. Slikkerveer. 1994. Taman Obat Keluarga (TOGA): Indigenous Indonesian Medicine for Self-reliance. Pp. 13-34 in The Cultural Dimension of Development: Indigenous Knowledge Systems. Edited by D.M. Warren, L.J. Slikkerveer \& D. Brokensha. Intermediate Technology Publications, London.

Soleri, D. \& D.A. Cleveland. 1993. Hopi Crop Diversity and Change. Journal of Ethnobiology 13:203-232.

Soleri, D. \& S.E. Smith. 1994. Morphological, Phenological and Genetic Comparisons of the Two Maize Varieties Conserved in situ and ex situ. Paper presented at the Annual Meeting of the Society for Economic, Mexico City.

SPSS. 1998. Systat Version 8, Chicago.

UNCED. 1992. United Nations Conference on Environment and Development. Rio de Janeiro.

Van der Burg, E. 1983. CANALS User's Guide. Department of Datatheory, Leiden University, Leiden.

Warren, D.M., L.J. Slikkerveer \& D.W. Brokensha. 1995. Editors of The Cultural Dimension of Development: Indigenous Knowledge Systems. IT Studies in Indigenous Knowledge and Development. Intermediate Technology Publications, London.

Wells , M. \& K. Brandon. 1993. The Principles and Practice of Buffer Zones and Local Participation in Biodiversity Conservation. Ambio 22:157-162.

Wells, M. 1995. Social-economic Strategies to Sustainably Use, Conserve and Share the Benefits of Biodiversity. Pp. 1016-1036 in Global Biodiversity Assessment. Edited by V.H. Heywood. UNEP/Cambridge University Press, Cambridge.

West, P.C. \& S.R. Brechin. 1991. Resident Peoples and National Parks: Social Dilemmas and Strategies in International Conservation. University of Arizona Press, Tucson.
Zent, S. \& E. Zent. 2001. Indigenous Knowledge (IK) Dynamics: A Critical Methodological Perspective. Paper presented at Building Bridges with Traditional Knowledge, an International Summit Meeting on Issues Involving Indigenous Peoples, Conservation, Sustainable Development and Ethnoscience. May 28-June 3, Honolulu, Hawai'i. 